\title{
Phytohormone Profiling reveals fungal Signatures and strong Manipulation of Infection Cycle in the Gymnosporangium juniper-virginianae Dual-Host Plant System
}

\begin{tabular}{|r|l|}
\hline Journal: & Botany \\
\hline Manuscript ID & cjb-2017-0178.R1 \\
\hline Danuscript Type: & Article \\
\hline Complete List of Authors: & $\begin{array}{l}\text { Moffatt, Kyle; Trent University, Biology } \\
\text { Monroy Flores, Carolina; ERM: Environmental Resources Management } \\
\text { Andreas, Peter; Trent University, Biology } \\
\text { Kisiala, Anna; Trent University, Biology } \\
\text { Emery, Neil; Trent University, Biology }\end{array}$ \\
\hline $\begin{array}{r}\text { Is the invited manuscript for } \\
\text { consideration in a Special } \\
\text { Issue? : }\end{array}$ & N/A \\
\hline Keyword: & $\begin{array}{l}\text { cedar-apple rust, gall-forming fungi, phytohormones, <i>cis</i>-Zeatin, } \\
\text { abscisic acid }\end{array}$ \\
\hline
\end{tabular}



cycle in the Gymnosporangium juniper-virginianae dual-host plant system

4 Kyle Moffatt - Trent University, Department of Biology, 2140 East Bank Drive, Peterborough,

$5 \quad$ K9J 7B8, ON, Canada (

6 Carolina Monroy Flores - Trent University, Department of Biology, 2140 East Bank Drive,

7 Peterborough, K9J 7B8, ON, Canada (carolinamnroy10@gmail.com $)$

8 Peter Andreas - Trent University, Department of Biology, 2140 East Bank Drive, Peterborough, 9 K9J 7B8, ON, Canada (peterandreas@trentu.ca)

10 Anna Kisiala - Trent University, Department of Biology, 2140 East Bank Drive, Peterborough, 11 K9J 7B8, ON, Canada (annakisiala@trentu.ca)

12 R.J. Neil Emery - Trent University, Department of Biology, 2140 East Bank Drive, 13 Peterborough, K9J 7B8, ON, Canada (nemery@trentu.ca)

15 Corresponding author: Peter Andreas - Trent University, Department of Biology, 2140 East

16 Bank Drive, Peterborough, K9J 7B8, ON, Canada, Tel.: 7057481011 (peterandreas@trentu.ca)

21 CMF current address - ERM: Environmental Resources Management, Mexico City, Mexico 
22 Abstract: The aim of this work was to examine the function of phytohormones in the

23 pathogenesis of cedar-apple rust, a fungal disease caused by Gymnosporangium juniper-

24 virginianae Schwein. on Eastern red cedar (Juniperus virginiana L.) and crabapple trees (Malus

25 spp. Mill.). Control cedar branchlets, gall tissues, fungal telial horns, as well as healthy and

26 infected apple leaves were collected throughout fungal and plant development and used for

27 profiling endogenous cytokinins (CK) and abscisic acid (ABA) by high performance liquid

28 chromatography-electrospray ionization-tandem mass spectrometry (HPLC-ESI-MS/MS).

29 Phytohormone composition implicates cytokinin involvement in the development of rust

30 infection. Moreover, increased levels of total CKs, as well as the unique profiles of sporulating

31 galls on cedar trees, telial horns, and infected apple leaves, dominated by cis-Zeatin (cZ) type

32 CK, suggest that the fungus can synthesize hormones to facilitate the infection process.

33 Distribution of ABA in the fungal and plant tissues indicates an important function of this stress

34 hormone in regulating rapid changes in osmotic pressure during teliospore production by the

35 galls. This study of the cedar-apple rust disease cycle is the first elucidation of phytohormones

36 profiling between a pathogenic fungus and the attacked plant in a dual-host infection system.

37 Key words: cedar-apple rust, gall-forming fungi, phytohormones, cytokinin, cis-Zeatin, abscisic 38 acid 


\section{Introduction}

Cedar-apple rust (Gymnosporangium juniper-virginianae) is an obligate, biotrophic,

41 heteroecious fungal parasite that infects apple tree leaves and fruits, while wind-born spores

42 travel and infect cedar trees, forming galls (Anikster 1985; Kolmer et al. 2009). The infected

43 apple trees are weakened, and rust growing on fruits significantly reduces their market value.

44 Consecutive years of infection may result in the failure to yield or even in death of the tree. The

45 fungus is a substantial threat to apple orchards since no effective preventative measures are

46 available. Currently, all cedar trees in a few kilometer radius must be destroyed, or costly and

47 often ineffective chemical treatments utilized (Ziems 2009). Moreover, the destruction of cedar

48 trees adjacent to orchards is not a sustainable approach as it impacts both the environment and

49 ecosystem. Cedar trees often act as a windbreak, preventing erosion in their vicinity (Ziems

50 2009; Gauthier and Heisdorffer 2015).

51 Figure 1 presents the life cycle of cedar-apple rust that involves two plant host species.

52 The fungus overwinters in spherical galls on cedar tree branchlets (C1). Early spring rains cause

53 horn-like structures (telial horns) to extrude from galls (C2). The horns become jelly-like and

54 swollen when they absorb water, while they dry to dark brown threads (C6) between the rain

55 periods. This swelling and drying of telial horns may occur quickly depending on the

56 environmental factors and can happen up to 10 times during the season. The telial horns contain

57 thousands of two-celled teliospores (C3). Each swelling/drying cycle causes the horns to be

58 pushed out further and expose more teliospores, until the supply is exhausted. Teliospores

59 germinate to produce a germ tube (basidium) (C4) from each cell. Four basidiospores are 
60 produced on each basidium. At optimum temperatures, basidiospores (C5) are produced within 4

61 hours of the horns absorbing water. Basidiospores are forcibly discharged into the air

62 immediately after being formed and can be carried long distances with the wind. After all the

63 teliospores have been exposed and all basidiospores released, the gall completes its part of the

64 life cycle, begins to dry up and eventually dies (C7). Basidiospores that land on young apple

65 leaves or fruits can germinate and infect the tissue if a film of water is present for an adequate

66 period of time. One to two weeks after the infection, orange pustules (pycnia) containing

67 pycniospores appear on the upper side of apple leaves (A1). One to two months after the

68 appearance of pycnia, the rust produces brownish clusters of threads or cylindrical tubes (aecia)

69 on the underside of the leaves or on fruits (A2). The aecia produce aeciospores (A3), which are

70 released into the air during dry conditions in late summer. Aeciospores that land on young cedar

71 twigs germinate, infect, and cause gall formation in the following year. Generally, the gall

72 matures and produces teliospores in the second year after infection, thereby continuing the

73 disease cycle. Because most galls produce teliospores for only one season, a new crop of galls is

74 required each year if infection of apple trees is to occur.

75 There are an estimated 7000 species of rust fungi that infect an array of vascular plants

76 from ferns to monocot and dicot species. Rust species have evolved specifically with the plant

77 hosts they infect, colonize, and upon which they reproduce (Kolmer et al. 2009). Host resistance

78 mechanisms include race non-specific resistance and race-specific resistance. Race non-specific

79 resistance can be attributed to a group of minor genes that provide defense against several

80 pathogens (Sekhwal et al. 2015). For instance, in maize a cluster of resistance genes called the 
81 rp1 complex have been shown to confer a race non-specific resistance response to rust (Hulbert

82 1997). In contrast, race-specific resistance involves plant resistance genes that recognize the

83 pathogen avirulence gene effectors, triggering the plant defense response (Sekhwal et al. 2015).

84 Infection occurs when the plant cannot recognize the rust, as either the rust isolates lack the 85 specific avirulence genes, or host plants lack the specific resistance genes (Huang et al. 2003).

86 Plants developed several defense mechanisms against pathogens. Primarily, constitutive

87 defenses provide resistance barriers like cell walls, waxy epidermal cuticles, and bark.

88 Secondarily, inducible defenses that stem from resistance genes, lessen or mediate pathogenic

89 infection by producing toxic chemicals such as pathogen-degrading enzymes. Rapid local

90 programmed cell death or hypersensitive response sequester infected cells to partition off

91 infected tissue, restricting resource allocation. Additionally, plant production of defense response

92 phytohormones, including jasmonic acid, salicylic acid and volatile organic compounds can

93 create an environment unfavorable to pathogen invasion or signal the regulation of other defense

94 factors (Freeman et al. 2008; Arya et al. 2014).

95 The mechanisms that involve hormone manipulation are adapted in many different 96 pathogenic systems to keep the host plant alive throughout parasitic life cycles (Tooker et al. 97 2008; Straka et al. 2010; Zhang et al. 2017). Biotrophic fungal pathogens often use 98 phytohormones such as cytokinin to successfully overcome plant defense barriers (Chanclud et 99 al. 2016; Chanclud and Morel 2016; Morrison et al. 2017; Patkar and Naqvi 2017). Cytokinins $100(\mathrm{CKs})$ are a group of growth regulators that have a key function in plant physiology. CKs are 101 essential for cell division and differentiation in plants, thus they are most abundant in the 
102 proliferating tissues. They play a role in the delay of senescence and the mobilization of nutrients

103 to the sink organs (Argueso et al. 2009; Werner and Schmülling 2009). Interestingly, CKs can be

104 produced by other organisms and used to manipulate the growth of plants. This inter-kingdom

105 hormone messaging may result in production of food, shelter or create a symbiotic relationship

106 between the organism and the plant (Stirk and van Staden 2010). Fungal derived cytokinins can

107 assist in side stepping a hypertensive response and delaying plant senescence through the

108 powerful ability to mobilize nutrients towards the sites of application (Walters and McRoberts

109 2006; Shigenaga and Argueso 2016). CKs produced by the gall forming fungal pathogen

110 Ustilago maydis (Persoon) Roussel cause differentiation of the phytohormone profiles in the

111 infected and uninfected tissues and are used to lessen plant ability to defend itself against the

112 invasion (Morrison et al. 2017). It was previously reported, that increased CKs levels affect

113 sugar and amino acid distribution around the site of infection to favor the fungus growth

114 (Chanclud et al. 2016).

115 Abscisic acid (ABA) is a hormone synthesized by plants under stress conditions and its

116 function is usually linked with defense mechanisms. The results of previous studies often support

117 a negative role of ABA in plant immunity (Cao et al. 2011). It has been suggested that ABA has

118 a role in increasing host susceptibility to pathogens and assists in gall formation (Mauch-Mani

119 and Mauch 2005). ABA has been proposed to have a stimulatory effect on gall formation and

120 development on hackberry trees (Straka et al. 2010). An antagonistic relationship between ABA

121 and salicylic acid which acts as a crucial plant defense mechanism has also been reported (Xu et

122 al. 2013). 
123 Our work investigates the CK and ABA phytohormone profiles within the unique cedar-

124 apple rust system throughout the life cycle of the fungus and its host plants, to better understand

125 the nature of the potential cross-species biochemical interactions. Based on the composition of

126 phytohormones observed during rust pathogenesis, we hypothesize that CKs and ABA are

127 involved in the formation and maintenance of galls on cedar trees and play a crucial role in other

128 stages of rust disease development. This is the first report of phytohormones signaling processes

129 between a pathogenic fungus and the attacked plant in a dual-host infection system.

\section{Materials and methods}

\section{Tissue Collection}

133 Samples were collected from both host trees grown in the area of Peterborough, Canada,

134 throughout the subsequent stages of rust infection development. The Eastern red cedar

135 (Juniperus virginiana) samples included: control, uninfected cedar branchlets (C0), pre-

136 sporulation gall (C1), dry sporulation gall (C6), and post-sporulation gall tissue (C7).

137 Additionally, both wet telial horns (C2) and dry telial horns (C6) were isolated separately from

138 the collected sporulating galls. The crabapple tree (Malus spp.) samples included: control,

139 uninfected leaf (A0) and fragments of infected leaves, containing pycnia (A1) on upper, and

140 aecia (A2) on bottom part of the tissue. Bracketed abbreviations of the different tissue types refer

141 to the labeling system used in Figure 1.

$142 \quad$ All the tested tissue types were collected in triplicates from three different plants and

143 weighed to $0.100 \mathrm{~g}$. Dissected samples were stored at $-20^{\circ} \mathrm{C}$ until further processing. 


\section{Hormone Extraction and Purification}

146 A modified protocol described by Quesnelle and Emery (2007) and Farrow and Emery

147 (2012) was used for the CK and ABA extraction. The tissues were suspended in Bieleski \#2

148 buffer $\left(\mathrm{CH}_{3} \mathrm{OH}: \mathrm{H}_{2} \mathrm{O}: \mathrm{HCOOH} \quad[15: 4: 1, \mathrm{v} / \mathrm{v} / \mathrm{v}]\right)$. Samples were spiked with internal standards

149 (144.7 $\mathrm{ng}$ of ${ }^{2} \mathrm{H}_{4}$-ABA (NRC-PBI, Saskatchewan, Canada)) and $10 \mathrm{ng}$ of each of the deuterated

150 internal standard CKs (OlChemim Ltd., Olomouc, Czech Republic; Table 1), and homogenized

151 in a ball mill (RetschMM300, Retsch $\mathrm{GmbH}$, Haan, Germany; $5 \mathrm{~min} / 25 \mathrm{~Hz}$ ) at $4^{\circ} \mathrm{C}$ with sterile

152 zirconium oxide grinding beads (Comeau Technique Ltd., Vaudreuil-Dorion, Canada). The

153 samples were allowed to extract passively overnight (approximately 12 hours) at $-20^{\circ} \mathrm{C}$. Pellets

154 were removed by centrifugation (Thermo Scientific; Model Sorvall ST16, Ottawa, Canada; 10

$155 \mathrm{~min}$ at $5000 \mathrm{RPM}$ ), the obtained extracts collected and samples were re-extracted with $1.0 \mathrm{~mL}$

156 extraction buffer at $-20^{\circ} \mathrm{C}$ for $30 \mathrm{~min}$. The pooled supernatants were dried in a speed vacuum

157 concentrator at $35^{\circ} \mathrm{C}$.

158 Extraction residues were reconstituted in $0.200 \mathrm{~mL}$ of $1 \mathrm{M}$ formic acid (pH 1.4) to ensure

159 complete protonation of all CKs. Each extract was purified on a mixed mode, reverse-phase,

160 cation-exchange cartridge (Oasis MCX, 2cc, 96-well plate; Waters, Mississauga, Canada) using

161 an automated liquid handling protocol (Model 215 SPE System; Gilson Inc., Middleton, USA).

162 Cartridges were activated with $1.0 \mathrm{~mL}$ of HPLC grade methanol and equilibrated using $1.0 \mathrm{~mL}$

163 of $1 \mathrm{M}$ formic acid ( $\mathrm{pH}$ 1.4). After equilibration, each sample was loaded and washed with 1.0

$164 \mathrm{~mL}$ of $1 \mathrm{M}$ formic acid $(\mathrm{pH} 1.4)$. ABA and $\mathrm{CKs}$ were eluted based on their chemical properties. 
165 ABA was eluted first using $1 \mathrm{~mL}$ of HPLC grade methanol. The nucleotide fraction (NTs) was 166 eluted using $1.0 \mathrm{~mL}$ of $0.35 \mathrm{M}$ ammonium hydroxide, free bases (FBs), ribosides (RBs), 167 methylthiols (METs), and glucosides (GLUCs) were retained on the column based on charge and 168 hydrophobic properties and, thus, these were eluted last using $1.0 \mathrm{~mL}$ of $0.35 \mathrm{M}$ ammonium 169 hydroxide in $60 \%$ methanol. All samples were dried in a speed vacuum concentrator at $35^{\circ} \mathrm{C}$, 170 and stored at $-20^{\circ} \mathrm{C}$ until further processing.

171 Nucleotides were dephosphorylated using 3 units of alkaline phosphatase (alkaline 172 phosphatase calf intestine; New England BioLabs, Whitby, Canada) in $1.0 \mathrm{~mL}$ of $0.100 \mathrm{M}$ 173 ethanolamine-HCL ( $\mathrm{pH} 10.4$ ) for 12 hours at $37^{\circ} \mathrm{C}$. The resulting RBs were brought to dryness in 174 a speed vacuum concentrator at $35^{\circ} \mathrm{C}$. Samples were re-constituted in $0.30 \mathrm{~mL}$ double distilled 175 Milli-Q water for further purification on a reversed-phase C18 column (C18, 2cc, 96-well plate; 176 Canadian Life Sciences, Peterborough, Canada). Columns were activated using 0.60 mL HPLC 177 grade methanol and equilibrated with $1.20 \mathrm{~mL}$ double distilled Milli-Q water. The samples were 178 loaded onto the C18 cartridge and allowed to pass through the column by gravity. The sorbent 179 was washed with $0.60 \mathrm{~mL}$ of Milli-Q water and resultant RBs were eluted using $1.0 \mathrm{~mL}$ HPLC 180 grade methanol. All sample eluents were dried in a speed vacuum concentrator at $35^{\circ} \mathrm{C}$ and 181 stored at $-20^{\circ} \mathrm{C}$ until further processing.

182 Prior to LC-MS/MS analysis, all dried samples were re-constituted in $1.50 \mathrm{~mL}$ of starting 183 conditions buffer $\left(\mathrm{CH}_{3} \mathrm{COOH}: \mathrm{CH}_{3} \mathrm{CN}: \mathrm{ddH}_{2} \mathrm{O} \quad[0.08: 5.0: 94.92, \mathrm{v} / \mathrm{v} / \mathrm{v}]\right.$ for $\mathrm{CKs}$, and $184 \mathrm{CH}_{3} \mathrm{COOH}: \mathrm{CH}_{3} \mathrm{OH}: \mathrm{ddH}_{2} \mathrm{O}[0.08: 5.0: 94.92, \mathrm{v} / \mathrm{v} / \mathrm{v}]$ for ABA). 


\section{Hormone Quantification and Analysis by HPLC-(ESI)-MS/MS}

Hormones were identified and quantified by HPLC-(ESI)-MS/MS (high performance

188 liquid chromatography - electrospray ionization - tandem mass spectrometry; Agilent 1100 series

189 HPLC (Santa Clara, USA) connected to a 5500 API Mass Spectrometer (AB Sciex, Framingham,

190 USA)). A $20 \mu \mathrm{L}$ sample volume was injected on a reversed-phase C18 column (Luna, $3 \mu \mathrm{m}, 150$

$191 \times 2.1 \mu \mathrm{m}$; Phenomenex, Torrance, USA); all CK samples were analyzed in positive-ion mode

192 (ESI+) and ABA samples were analyzed in negative-ion mode (ESI-). CKs were eluted with an

193 increasing gradient of $0.08 \%$ acetic acid in acetonitrile (A) mixed with $0.08 \%$ acetic acid in

194 double distilled water (B) at a flow rate of $0.2 \mathrm{~mL} \mathrm{~min}^{-1}$. The initial conditions were $5 \% \mathrm{~A}$ and

$19595 \% \mathrm{~B}$, changing linearly in 17 minutes to $95 \% \mathrm{~A}$ and $5 \% \mathrm{~B}$. Conditions remained constant for 5

196 minutes, and then immediately returned back to initial conditions for 18 minutes. ABA was

197 eluted using component $\mathrm{A}: \mathrm{H}_{2} \mathrm{O}$ with $0.08 \% \mathrm{CH}_{3} \mathrm{CO}_{2} \mathrm{H}$ and component $\mathrm{B}$ : $\mathrm{CH}_{3} \mathrm{OH}$ with $0.08 \%$

$198 \mathrm{CH}_{3} \mathrm{CO}_{2} \mathrm{H}$, at a flow rate of $0.2 \mathrm{~mL} \mathrm{~min}^{-1}$. Initial conditions for the $\mathrm{ABA}$ fraction were $50 \% \mathrm{~B}$

199 changing on a linear gradient to $80 \%$ B over 8 minutes. This ratio was then held constant for 2

200 minutes before returning to starting conditions and equilibrating for 8 minutes. The effluent was

201 introduced into the electrospray source (source block temperature of $700^{\circ} \mathrm{C}$ ), and $\mathrm{CKs}$ and $\mathrm{ABA}$

202 were identified based on their MRM channels and retention times.

203 All data were analyzed using Analyst (v 1.5) software (AB Sciex, Framingham, USA), to

204 calculate peak area. Quantification was achieved through isotope dilution analysis based on the 205 recovery of ${ }^{2} \mathrm{H}$-labelled internal standards, in accordance with those listed in Table 1. 


\section{Results}

208 Full CK and ABA profiles of all the tissue types analyzed in this work are presented in

209 Table 2 and further interpretation of the most significant findings in Figures 2 and 3. Among all

210 the samples collected from cedar trees, sporulation galls contained the highest amount of total

211 CKs (Figure 2). In the apple system, infected leaves contained 2.5 times more of the total CKs

212 than the uninfected leaves.

213 Mass spectrometric analysis revealed distinctive profiles of cZ (cis-Zeatin) type

214 cytokinins among the tested plant and fungal tissues (Figure 3). Within the cedar system, the

215 highest levels of $\mathrm{cZ}$ forms were detected in sporulation gall samples. cis-Zeatin levels of

216 sporulation galls were composed of active free bases (FB) and precursor nucleotide (NT) forms.

217 On the contrary, post-sporulation galls showed a decrease in overall cZ level and no active FB

218 forms. Wet telial horns, comprised entirely of fungal resting spores (teliospores), contained

219 lower levels of $\mathrm{cZ}$ forms than the other analyzed tissues; however, cZ types were the only CKs

220 present in this sample type. FB, RB, and NT forms of cis-Zeatin were not detected in the control

221 cedar branchlets and present only in very low quantities during pre-sporulation development.

222 Within the apple system, cZ form levels (FB, RB, and NT) were significantly higher in the rust

223 infected leaves, compared to the healthy, control apple leaves.

224 Abscisic acid (ABA) was present in great abundance in all eight tissue types (Table 2).

225 Each of the three stages of gall development showed strikingly higher levels of ABA than the

226 cedar branchlet controls. Sporulation galls contained the highest amount of ABA of all the tested

227 tissues, which was over 28 times higher than ABA level detected in cedar branchlet controls. 
228 ABA level was slightly higher in the dry telial horns than in the wet telial horns. ABA was also

229 the only phytohormone found in the dry telial horns. Remarkably, control apple leaves contained

$230 \quad 1.5$ times higher ABA levels than the infected leaves.

232 Discussion

233 The mass-spectrometric examination of a wide range of cytokinin and ABA metabolites

234 showed that phytohormone profiles clearly differ between the two host plants, and also revealed

235 a very unique CK composition that was characteristic for the pathogen samples. The dynamics of

236 cytokinin production during plant infection suggests their strong relationship with the rust

237 lifecycle. We consider two potential mechanisms to explain our findings. The first is that the

238 fungus is able to manipulate host CK biochemical pathway by redirecting CKs produced by plant

239 to facilitate infection, or second, that the pathogen is producing CKs itself which in turn suggests

240 the existence of a CK metabolic pathway within rust.

241 For both hosts the tissues undergoing sporulation (galls and infected apple leaves)

242 contained the highest levels of total CKs (Figure 2). The sporulating galls are composed of both

243 plant tissue and fungal teliospores. CKs found within these organs included tZ, cZ, and iP forms.

244 Meanwhile, isolated from sporulating galls wet telia that are composed only of teliospores,

245 contained just cZR and cZNT. On the other hand, no active FB fraction and no cZ form CKs

246 were detected in cedar control twigs. In a similar manner, infected apple tissue comprised of

247 pycnia on the upper (adaxial) and aecia on the lower (abaxial) leaf surface where the aeciospore

248 production occurs, had much different hormone profiles than the non-infected control leaves. 
249 Significant shift from $\mathrm{tZ}$ to $\mathrm{cZ}$ type in hormone profiles during rust infection and disease 250 development suggests that the fungus is excreting hormones using the common or modified 251 mevalonate (MVA) pathway, similar to the one described for $U$. maydis, a fungus infecting corn 252 (Morrison et al. 2015a, 2017) and consistent with the signature CK pathway reported from a 253 large survey of fungal species (Morrison et al. 2015b). On the contrary, in the non-infected 254 control cedar twigs and apple leaves the plant methylerythritol phosphate (MEP) pathway was 255 shown to be more active, resulting in production of the $\mathrm{tZ}$ isomers, as well as $\mathrm{DZ}$ and iP type 256 CKs (Morrison et al. 2015a).

257 We propose that the fungal derived cZ type CKs are modifying the host plant nutrient 258 flux by stimulating and maintaining the source-sink relationship to promote a nutrient enriched 259 environment where fungal development is facilitated. Additionally, the virulence of the infection 260 may be modified by CK activity. The reduced virulence of fungal pathogen infection has been 261 linked to the moderation of CK biosynthesis in rice blast fungus (Chanclud et al. 2016) and to 262 differing levels of virulence among U. maydis strains (Morrison et al. 2017). Further 263 investigation of the host CK response regulator genes may help to unveil new approaches leading 264 to better understanding of susceptibility and resistance factors in both cedar and apple trees 265 affected by G. juniper-virginianae (Arya et al. 2014; Sekhwal et al. 2015).

266 Abscisic acid was present in a great abundance in all tissues tested; however, ABA 267 patterns were different between the two host plant species when comparing infected tissue to the 268 controls. Sporulation galls contained ABA levels that were, astonishingly, 28-fold greater than 269 the already high levels of healthy cedar branchlets. Such high ABA concentration may be 
270 attributed to cedar response to stress factors, namely rust development and sporulation occurring

271 in the galls. However, high levels of ABA were detected in both wet and dry telial horns, which

272 are composed solely of rust teliospores; thus, we suggest that at least part of the ABA was of

273 fungal origin. Production of significant quantities of ABA was previously reported in axenic

274 cultures of another fungal pathogen, U. maydis (Bruce et al. 2011). Exogenous ABA application

275 on susceptible rice leaf sheaths has been shown to increase susceptibility and disease responses

276 to rice blast fungus, Magnaporthe grisea (T.T. Hebert) M.E. Barr (Koga et al. 2004). Based on

277 the available literature and the results of this investigation we propose that the ABA derived

278 from G. juniper-virginianae can mediate host susceptibility within the cedar system.

279 Extraordinarily high levels of ABA detected in the sporulation galls may be attributed to their

280 extensive tissue proliferation. Cedar galls are large morphological structures that undergo rapid

281 and recurrent changes of moisture content required for teliospore production and germination.

282 This part of rust life cycle involves precise osmotic regulation and ABA is known as an

283 important regulator of osmotic pressure and water permeability through aquaporins (Beaudette et

284 al. 2007) and thus, may assist in promoting a moisture regulated environment for the benefit of

285 the pathogen (Cao et al. 2011).

286 Contrary to the pattern in cedar, ABA level was higher in the control within the crabapple

287 system, for which healthy leaves contained more ABA than in the leaves of the infected trees.

288 This is not consistent with the hypothesis that it is involved with a stress response mechanism

289 induced by the fungus. However, we consider the option that each host plant species responds

290 uniquely to the pathogen presence and in the stage of apple leaf rust ABA may not be required 
291 and therefore not produced by the pathogen but instead, may be derived solely from the stressed

292 apple plant. The different mechanism of ABA may be a reflection of the different manifestations

293 of the disease whereby the cedar responds with a large gall structure and the apple tree has a less

294 complex fungal infection spot.

\section{Conclusion}

The observed dynamics in cytokinin and abscisic acid profiles during cedar-apple rust

298 infection process provides an interesting model to evaluate phytohormone involvement in

299 Gymnosporangium juniper-virginianae pathogenesis. Significant changes in hormone

300 composition during fungus lifecycle depict an active relationship between the rust and host

301 plants throughout cedar gall growth and sporulation, and apple rust infection. An abundance of

302 cZ type CKs within the telial horns and the fungus infected tissues points towards their common

303 origin and suggests that fungal derived CKs are a necessary factor for the disease development.

304 Additional research involving cedar and apple defense response phytohormones might

305 further shed more light onto the parasitic relationship between rust and its hosts leading to better

306 understanding of G. juniper-virginianae mode of action in the infected plants and ultimately

307 better strategies involving hormonal treatments in order to deal with infected orchards.

\section{References}


310 Anikster, Y. 1985. The formae speciales. In The cereal rusts. Vol. 1. Edited by W.R. Bushnell,

311 A.P. Roelfs. Academic Press, Inc., Orlando. pp. 115-130. Available from

312 http://www.globalrust.org/sites/default/files/cereal-rusts/volume2.pdf.

313 Argueso, C.T., Ferreira, F.J., and Kieber, J.J. 2009. Environmental perception avenues: the 314 interaction of cytokinin and environmental response pathways. Plant Cell Environ. 32(9): 315 1147-1160. doi: 10.1111/j.1365-3040.2009.01940.x.

316 Arya, P., Kumar, G., Acharya, V., and Singh, A.K. 2014. Genome-wide identification and 317 expression analysis of NBS-encoding genes in Malus $x$ domestica and expansion of NBS 318 genes family in Rosaceae. PLoS ONE, 9(9): e107987. doi: 10.1371/journal.pone.0107987.

319 Beaudette, P.C., Chlup, M., Yee, J., and Emery, R.J.N. 2007. Relationships of root conductivity 320 and aquaporin gene expression in Pisum sativum: diurnal patterns and the response to 321 $\mathrm{HgCl}_{2}$ and ABA. J. Exp. Bot. 58(6): 1291-1300. doi: 10.1093/jxb/erl289.

322 Bruce, S.A., Saville, B.J., and Emery, R.J.N. 2011. Ustilago maydis produces cytokinins and 323 abscisic acid for potential regulation of tumor formation in maize. J. Plant Growth Regul. 30(1): 51-63. doi: 10.1007/s00344-010-9166-8.

325 Cao, F.Y., Yoshioka, K., and Desveaux, D. 2011. The role of ABA in plant-pathogen 326 interactions. J. Plant Res. 124(4): 489-499. doi: 10.1007/s10265-011-0409-y.

327 Chanclud, E., Kisiala, A., Emery, R.J.N., Chalvon, V., Ducasse, A., Romiti-Michel, C., Gravot, 328 A., Kroj, T, and Morel, JB. 2016. Cytokinin production by the rice blast fungus is a pivotal 329 requirement for full virulence. PLoS Pathog. 12(2): e1005457. doi: $330 \quad$ 10.1371/journal.ppat.1005457. 
331 Chanclud, E., and Morel, J.B. 2016. Plant hormones: a fungal point of view. Mol. Plant Pathol. 332 17(8): 1289-1297. doi: 10.1111/mpp.12393.

333 Farrow, S.C., and Emery, R.J.N. 2012. Concurrent profiling of indole-3-acetic acid, abscisic 334 acid, and cytokinins and structurally related purines by high-performance-liquid335 chromatography tandem electrospray mass spectrometry Plant Methods, 8-42. doi: $10.1186 / 1746-4811-8-42$.

337 Freeman, B.C., and Beattie, G.A. 2008. An overview of plant defenses against pathogens and 338 herbivores. The Plant Health Instructor. doi: 10.1094/PHI-I-2008-0226-01.

339 Gauthier, N.W., and Heisdorffer, A.M. 2015. Apple rust diseases. University of Kentucky, 340 College of Agriculture, Food and Environment. Plant Pathology Fact Sheet. PPFS-FR-T341 05. Available from http://plantpathology.ca.uky.edu/files/ppfs-fr-t-05.pdf.

342 Koga, H., Dohi, K., and Mori, M. 2004. Abscisic acid and low temperatures suppress the whole 343 plant-specific resistance reaction of rice plants to the infection of Magnaporthe grisea. Physiol. Mol. Plant Pathol. 65(1): 3-9. doi: 10.1016/j.pmpp.2004.11.002.

345 Kolmer, J.A., Ordonez, M.E., and Groth, J.V. 2009. The rust fungi. In eLS. John Wiley \& Sons, $346 \quad$ Ltd, Chichester. doi: 10.1002/9780470015902.a0021264.

347 Hulbert, S.H. 1997. Structure and evolution of the rp1 complex conferring rust resistance in 348 maize. Annu. Rev. Phytopathol. 35: 293-310. doi: 10.1146/annurev.phyto.35.1.293

349 Huang, L., Brooks, S.A., Li, W., Fellers, J.P., Trick, H.N., and Gill, B.S. 2003. Map-based 350 cloning of leaf rust resistance gene Lr21 from the large and polyploid genome of bread 351 wheat. Genetics, 164(2): 655-664. PMID: 12807786. 
352 Mauch-Mani, B., and Mauch, F. 2005. The role of abscisic acid in plant-pathogen interactions.

353 Curr. Opin. Plant Biol. 8(4): 409-414. doi: 10.1016/j.pbi.2005.05.015.

354 Morrison, E.N., Emery, R.J.N., and Saville, B.J. 2015a. Phytohormone involvement in the

355 Ustilago maydis-Zea mays pathosystem: relationships between abscisic acid and cytokinin

356 levels and strain virulence in infected cob tissue. PLoS ONE, 10(6): e0130945. doi:

$357 \quad$ 10.1371/journal.pone.0130945.

358 Morrison, E.N., Knowles, S., Hayward, A., Thorn, R.G., Saville, B.J., and Emery, R.J.N. $2015 b$.

359 Detection of phytohormones in temperate forest fungi predicts consistent abscisic acid

360 production and a common pathway for cytokinin biosynthesis. Mycologia, 107(2): 245-

$361 \quad$ 257. doi: $10.3852 / 14-157$.

362 Morrison, E.N., Emery, R.J.N., and Saville, B.J. 2017. Fungal derived cytokinins are necessary

363 for normal Ustilago maydis infection in maize. Plant Pathol. 66(5): 726-742. doi:

$364 \quad 10.1111 /$ ppa.12629.

365 Patkar, R.N., and Naqvi, N.I. 2017. Fungal manipulation of hormone-regulated plant defense.

366 PLoS Pathog. 13(6): e1006334. doi: 10.1371/journal.ppat.1006334.

367 Quesnelle, P., and Emery, R.J.N. 2007. cis-cytokinins that predominate in Pisum sativum during 368 early embryogenesis will accelerate embryo growth in vitro. Can. J. Bot. 85(1): 91-103.

369 doi: $10.1139 / \mathrm{b} 06-149$.

370 Sekhwal, M.K., Li, P., Lam, I., Wang, X., Cloutier, S., and You, F.M. 2015. Disease resistance

371 gene analogs (RGAs) in plants. Int. J. Mol. Sci. 16(8): 19248-19290. doi:

$372 \quad 10.3390 /$ ijms 160819248. 
373 Shigenaga A.M, and Argueso, C.T. 2016. No hormone to rule them all: interactions of plant 374 hormones during the responses of plants to pathogens. Semin. Cell Dev. Biol. 56: 174-189. 375 doi: $10.1016 /$ j.semcdb.2016.06.005.

376 Stirk, W.A., and van Staden, A. 2010. Flow of cytokinins through the environment. Plant Growth 377 Regul. 62(2): 110-116. doi: 10.1007/s10725-010-9481-x.

378 Straka, J.R., Hayward, A.R., and Emery, R.J.N. 2010. Gall-inducing Pachypsylla celtidis 379 (Psyllidae) infiltrate hackberry trees with high concentrations of phytohormones. J. Plant 380 Interact. 5(3): 197-203. doi: 10.1080/17429145.2010.484552.

381 Tooker, J.F., Rohr, J.R., Abrahamson, W.G., and De Moraes, C.M. 2008. Gall insects can evade 382 and alter indirect plant defenses. New Phytol. 178(3): 657-671. doi: 10.1111/j.1469-

384 Walters, D.R., and McRoberts, N. 2006. Plants and biotrophs: a pivotal role for cytokinins? 385 Trends Plant Sci. 11(12): 581-586. doi: 10.1016/j.tplants.2006.10.003.

386 Werner, T., and Schmülling, T. 2009. Cytokinin action in plant development. Curr. Opin. Plant 387 Biol. 12(5): 527-537. doi: 10.1016/j.pbi.2009.07.002.

388 Xu, J., Audenaert, K., Hofte, M., and De Vleesschauwer, D. 2013. Abscisic acid promotes 389 susceptibility to the rice leaf blight pathogen Xanthomonas oryzae pv oryzae by suppressing salicylic acid-mediated defenses. PLoS One, 8(6): e67413. doi: 10.1371/journal.pone.0067413. 
392 Zhang, H., Guiguet, A., Dubreuil, G., Kisiala, A., Andreas, P., Emery, R.J.N., Huguet, E., Body, 393 M., and Giron, D. 2017. Dynamics and origin of cytokinins involved in plant manipulation 394 by a leaf-mining insect. Insect Sci. doi:10.1111/1744-7917.12500.

395 Ziems, A.D. 2009. Cedar-apple and related rusts of apple and ornamentals. University of 396 Nebraska - Lincoln Extension, Institute of Agriculture and Natural Resources. NebGuide. 397 G1907. Available from: http://extensionpublications.unl.edu/assets/pdf/g1907.pdf. 
399 Table 1. Endogenous hormones and labeled CK standards, scanned for by liquid 400 chromatography-electrospray ionization-tandem mass spectrometry (HPLC-(ESI)-MS/MS). 401 Deuterated internal standards purchased from OlChemim Ltd. (Olomouc, Czech Republic) 402 (cytokinin) and National Research Council-Plant Biotechnology Institute (NRC-PBI, Saskatoon, 403 Saskatchewan, CA) (ABA) were used for the analysis.

\begin{tabular}{|c|c|}
\hline Hormone & $\begin{array}{l}{ }^{2} \text { H-labeled internal } \\
\text { standard }\end{array}$ \\
\hline \multicolumn{2}{|l|}{ Nucleotides (NT) } \\
\hline $\begin{array}{l}\text { 1. } \quad \text { Trans-zeatin riboside-5'-monophosphate }(t \mathrm{ZNT}) \\
\text { 2. } \quad \text { Cis-zeatin riboside-5' -monophosphate }(c \mathrm{ZNT})\end{array}$ & ${ }^{2} \mathrm{H}_{5}[9 \mathrm{RMP}] \mathrm{Z}$ \\
\hline $\begin{array}{l}\text { Dihydrozeatin riboside }-5 \text { '-monophosphate } \\
\text { (DHZNT) }\end{array}$ & ${ }^{2} \mathrm{H}_{3}[9 \mathrm{RMP}] \mathrm{DHZ}$ \\
\hline 4. $\quad \mathrm{N}^{6}$-isopentyladenosine-5'monophosphate (iPNT) & ${ }^{2} \mathrm{H}_{6}[9 \mathrm{RMP}] \mathrm{iP}$ \\
\hline \multicolumn{2}{|l|}{ Ribosides (RB) } \\
\hline $\begin{array}{ll}\text { 5. } & \text { Trans-zeatin riboside }(t \mathrm{ZR}) \\
\text { 6. } & \text { Cis-zeatin riboside }(c \mathrm{ZR})\end{array}$ & ${ }^{2} \mathrm{H}_{5}[9 \mathrm{R}] \mathrm{Z}$ \\
\hline 7. Dihydrozeatin riboside (DHZR) & ${ }^{2} \mathrm{H}_{3}[9 \mathrm{R}] \mathrm{DHZ}$ \\
\hline 8. $\quad \mathrm{N}^{6}$-isopentyladenosine (iPR) & ${ }^{2} \mathrm{H}_{6}[9 \mathrm{R}] \mathrm{iP}$ \\
\hline \multicolumn{2}{|l|}{ Free bases $(\mathrm{FB})$} \\
\hline 9. $\quad$ Trans-zeatin $(t Z)$ & \\
\hline 10. Cis-zeatin $(c \mathrm{Z})$ & ${ }^{2} \mathrm{H}_{3} \mathrm{DHZ}$ \\
\hline 11. Dihydrozeatin (DHZ) & \\
\hline 12. $\mathrm{N}^{6}$-isopentyladenine (iP) & ${ }^{2} \mathrm{H}_{6} \mathrm{iP}$ \\
\hline \multicolumn{2}{|l|}{ Glucosides (GLUC) } \\
\hline $\begin{array}{l}\text { 13. } \\
\text { 14. }\end{array}$ & ${ }^{2} \mathrm{H}_{5} \mathrm{ZOG}$ \\
\hline 15. Dihydrozeatin-O-glucoside (DHZOG) & ${ }^{2} \mathrm{H}_{7} \mathrm{DHZOG}$ \\
\hline 16. Trans-zeatin-O-glucoside riboside ( $t \mathrm{ZROG})$ & ${ }^{2} \mathrm{H}_{5} \mathrm{ZROG}$ \\
\hline
\end{tabular}


17. Cis-zeatin-O-glucoside riboside $c$ ZROG

18. Dihydrozeatin-O-glucoside riboside (DHZROG) $\quad{ }^{2} \mathrm{H}_{7} \mathrm{DHZROG}$

19. Trans-zeatin-9-glucoside $(\mathrm{ZZ} 9 \mathrm{G})$

20. Cis-zeatin-9-glucoside (cZ9G)

${ }^{2} \mathrm{H}_{5} \mathrm{Z} 9 \mathrm{G}$

21. Dihydrozeatin-9-glucoside (DHZ9G)

${ }^{2} \mathrm{H}_{3} \mathrm{DHZ9G}$

22. N6-Isopentenyladenine-7-glucoside (iP7G)

${ }^{2} \mathrm{H}_{5} \mathrm{iP} 7 \mathrm{G}$

23 N6-Isopentenyladenine-9-glucoside (iP9G)

Methylthiols (MET)

24. 2-Methylthio-trans-zeatin (2MeSZ) $\quad{ }^{2} \mathrm{H}_{5} \mathrm{MeSZ}$

25. 2- Methylthio-trans-zeatin riboside (2MeSZR) $\quad{ }^{2} \mathrm{H}_{5} \mathrm{MeSZR}$

26. 2-Methylthio- ${ }^{6}$-isopentyladenine (2MeSiP) $\quad{ }^{2} \mathrm{H}_{6} \mathrm{MeSiP}$

27. 2-Methylthio- $\mathrm{N}^{6}$-isopentyladenosine (2MeSiPA) $\quad{ }^{2} \mathrm{H}_{6} \mathrm{MeSiPR}$

Aromatic cytokinins

26 Benzyloaminopurine (BA) ${ }^{2} \mathrm{H}_{7} \mathrm{BA}$

27 Benzyloaminopurine riboside (BAR) ${ }^{2} \mathrm{H}_{7} \mathrm{BAR}$

28 Abscisic acid (ABA) ${ }^{2} \mathrm{H}_{4} \mathrm{ABA}$


407 Table 2. Concentrations of CKs and ABA isolated from cedar branchlet control, pre-sporulation

408 galls, sporulation galls, post-sporulation galls, wet telial horns, dry telial horns, apple leaf control

409 and infected leaf (means \pm SE, $n=3$ ).

410

\begin{tabular}{|c|c|c|c|c|c|c|c|c|}
\hline \multicolumn{9}{|c|}{ Hormone level [pmol $\left.\mathrm{g} \mathrm{fwt}^{-1}\right]$} \\
\hline \multicolumn{7}{|c|}{ Eastern Red Cedar Host } & \multicolumn{2}{|c|}{ Crabapple Host } \\
\hline & $\begin{array}{c}\text { Branchlet } \\
\text { Control }\end{array}$ & $\begin{array}{c}\text { Pre- } \\
\text { Sporulation } \\
\text { Gall }\end{array}$ & $\begin{array}{l}\text { Sporulation } \\
\text { Gall }\end{array}$ & $\begin{array}{c}\text { Post } \\
\text { Sporulation } \\
\text { Gall }\end{array}$ & $\begin{array}{c}\text { Wet Telial } \\
\text { Horn }\end{array}$ & $\begin{array}{c}\text { Dry Telial } \\
\text { Horn }\end{array}$ & Leaf Control & $\begin{array}{l}\text { Infected } \\
\text { Leaf }\end{array}$ \\
\hline cisZNT & - & - & $20.65 \pm 3.14$ & $12.89 \pm 3.51$ & $3.53 \pm 0.37$ & - & $28.20 \pm 15.64$ & $481.33 \pm 17.41$ \\
\hline iPNT & $5.37 \pm 0.64$ & $3.53 \pm 0.14$ & $4.29 \pm 0.19$ & $5.17 \pm 0.38$ & - & - & $37.16 \pm 4.63$ & $69.58 \pm 4.19$ \\
\hline Total & $5.37 \pm 0.64$ & $3.53 \pm 0.14$ & $24.93 \pm 3.12$ & $18.06 \pm 3.83$ & $3.53 \pm 0.37$ & - & $65.36 \pm 20.04$ & $550.91 \pm 21.25$ \\
\hline DZR & $3.33 \pm 0.68$ & $5.11 \pm 0.03$ & - & $4.34 \pm 0.20$ & - & - & - & - \\
\hline tZR & $1.74 \pm 0.20$ & $1.30 \pm 0.25$ & $3.47 \pm 0.63$ & $3.57 \pm 0.68$ & - & - & - & - \\
\hline cisZR & - & $1.25 \pm 0.16$ & - & $2.18 \pm 0.34$ & $1.24 \pm 0.11$ & - & $9.57 \pm 1.52$ & $160.30 \pm 3.25$ \\
\hline iPR & $20.24 \pm 1.72$ & $5.75 \pm 1.10$ & $31.31 \pm 3.49$ & $7.28 \pm 0.70$ & - & - & $327.07 \pm 37.68$ & $200.76 \pm 10.85$ \\
\hline Total & $25.31 \pm 1.99$ & $13.41 \pm 0.88$ & $34.78 \pm 3.78$ & $17.37 \pm 1.58$ & $1.24 \pm 0.11$ & - & $336.64 \pm 39.03$ & $361.06 \pm 8.31$ \\
\hline $\mathrm{DZ}$ & - & - & - & - & - & - & - & $29.73 \pm 0.89$ \\
\hline $\mathrm{tZ}$ & - & - & $19.26 \pm 2.60$ & - & - & - & $4.07 \pm 0.48$ & $14.63 \pm 1.13$ \\
\hline cis $Z$ & - & - & $26.84 \pm 3.95$ & - & - & - & - & $99.63 \pm 11.67$ \\
\hline iP & - & - & $9.51 \pm 1.04$ & - & - & - & $8.50 \pm 0.65$ & $7.06 \pm 0.35$ \\
\hline Total & - & - & $55.61 \pm 1.14$ & - & - & - & $12.57 \pm 0.66$ & $151.04 \pm 11.43$ \\
\hline tZROG & - & - & - & - & - & - & $24.47 \pm 4.22$ & $32.10 \pm 3.07$ \\
\hline $\mathrm{tZOG}$ & - & $2.71 \pm 0.43$ & - & $7.92 \pm 1.73$ & - & - & $9.71 \pm 1.23$ & $9.03 \pm 1.16$ \\
\hline Total & - & $2.71 \pm 0.43$ & - & $7.92 \pm 1.73$ & - & - & $34.18 \pm 3.75$ & $41.13 \pm 4.01$ \\
\hline MeSZR & - & - & - & - & - & - & $29.12 \pm 1.38$ & $90.21 \pm 6.47$ \\
\hline Total & - & - & - & - & - & - & $29.12 \pm 1.38$ & $90.21 \pm 6.47$ \\
\hline \multirow[t]{2}{*}{$\overline{\mathbf{A B A}}$} & $96740.45 \pm$ & $870360.38 \pm$ & $2717446.85 \pm$ & $1967788.68 \pm$ & $30170.55 \pm$ & $41515.73 \pm$ & $124831.41 \pm$ & $82532.04 \pm$ \\
\hline & 204414.48 & 5679.11 & 205476.73 & 204414.48 & 8094.12 & 2877.68 & 8327.92 & 8870.5 \\
\hline
\end{tabular}

411 


\section{Figure captions}

414

415 Figure 1. Gymnosporangium juniper-virginianae life cycle: (C0) red cedar branchlet; (C1) pre-

416 sporulation gall; (C2) sporulation gall with wet telial horns containing teliospores; (C3)

417 teliospores isolated from telial horns; (C4) basidia produced from germinating teliospores; (C5)

418 basidiospores discharged into the air; (C6) sporulation gall with dry telial horns exposed; (C7)

419 post-sporulation gall after release of teliospores; (A0) apple tree leaf; (A1) pycnia appearing on

420 top of apple leaf; (A2) aecium formed on the lower side of apple leaf; (A3) aeciospores after

421 being ejected from the aecium (more details in the text).

422

423 Figure 2. Levels of total cytokinins in the analyzed cedar, rust and apple tree samples (means \pm 424 SE, $n=3)$.

425

426 Figure 3. Total cZ type cytokinin concentrations including FB, RB, and NT in the analyzed: A)

427 cedar and rust, and B) apple tree samples (means $\pm \mathrm{SE}, n=3$ ).

428 


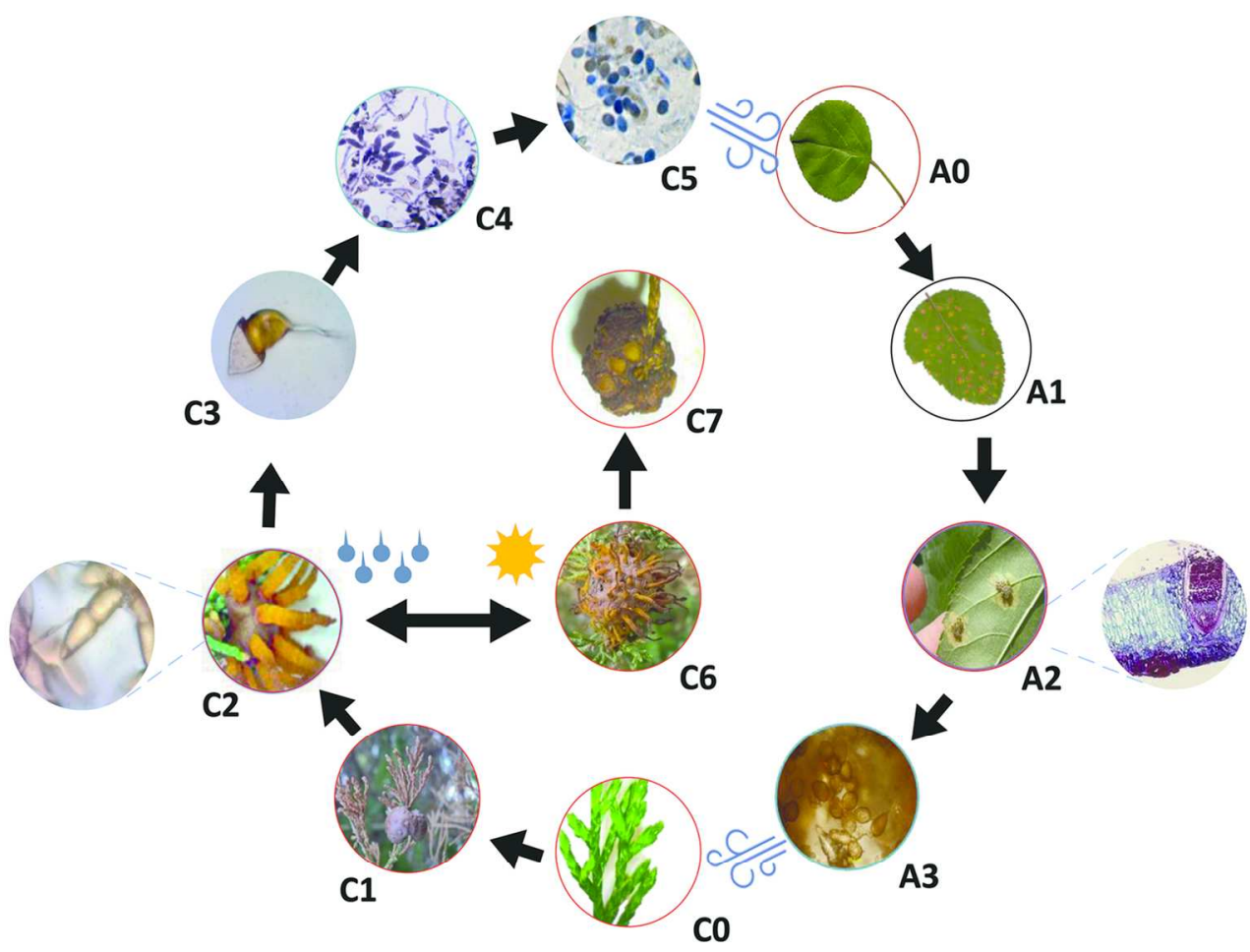

Figure 1. Gymnosporangium juniper-virginianae life cycle: (C0) red cedar branchlet; (C1) pre-sporulation gall; (C2) sporulation gall with wet telial horns containing teliospores; (C3) teliospores isolated from telial horns; (C4) basidia produced from germinating teliospores; (C5) basidiospores discharged into the air; (C6) sporulation gall with dry telial horns exposed; (C7) post-sporulation gall after release of teliospores; (A0) apple tree leaf; (A1) pycnia appearing on top of apple leaf; (A2) aecium formed on the lower side of apple leaf; (A3) aeciospores after being ejected from the aecium (more details in the text).

$144 \times 114 \mathrm{~mm}(300 \times 300 \mathrm{DPI})$ 


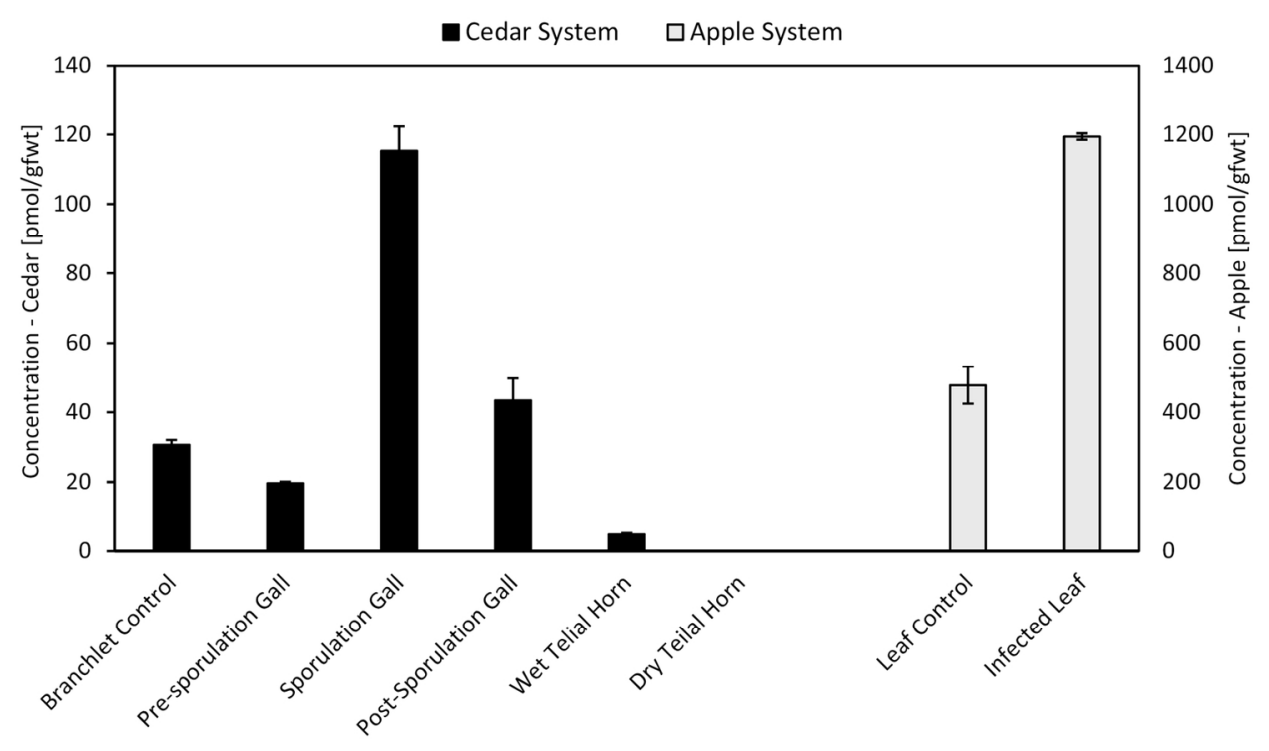

Figure 2. Levels of total cytokinins in the analyzed cedar, rust and apple tree samples (means $\pm S E, n=3$ ). $147 \times 88 \mathrm{~mm}(300 \times 300 \mathrm{DPI})$ 

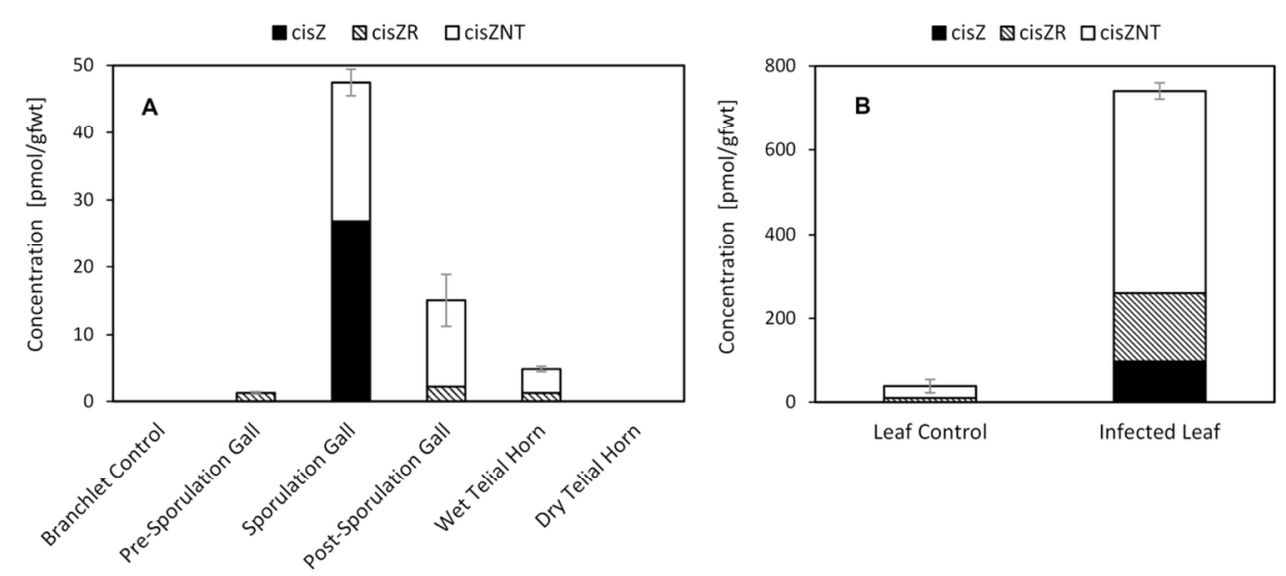

Figure 3. Total $c Z$ type cytokinin concentrations including FB, RB, and NT in the analyzed: A) cedar and rust, and $\mathrm{B}$ ) apple tree samples (means $\pm \mathrm{SE}, \mathrm{n}=3$ ).

$106 \times 48 \mathrm{~mm}(300 \times 300 \mathrm{DPI})$ 